\title{
Evolution of written language technology and not state building causes positive economic growth
}

\author{
Naess, Halvor MD, PhD
}

University of Bergen, Pb 7800, 5020 Bergen, Norway, haln@haukeland.no

\begin{abstract}
Creativity means the formation or discovery of something that is new, surprising and valuable (true, meaningful, beautiful, useful). Products of creativity include innovations, economic goods, and institutions underlying economic growth. It has previously been shown that creativity in all domains is based on selectionist mechanisms dependent on discrete representation such as the alphabet. Using historical data on energy capture as a proxy for economic growth, this paper shows that positive economic growth the last 11,000 years was significantly associated with the sophistication of information technology and literacy rate, but not state or society organization (despotic, non-despotic or anarchic).
\end{abstract}

KEYWORDS: literacy, alphabet, printing, state, anarchy, growth

\section{INTRODUCTION}

It is generally acknowledged that human flourishing depends on liberty. Most scholars believe that the nondespotic state is a necessary guarantor for liberty by securing rule of law, providing necessary infrastructure and inhibiting draconian social sanctions (Acemoglu and Robinson 2019). However, theories of creativity suggest that cultural evolution is associated with evolution of the information technology and not state building. State building is likely coincident to creative social evolution unleashed by improved literary tools such as the alphabet and the printing press.

Creativity means the formation or discovery of something that is new, surprising and valuable (true, meaningful, beautiful, useful). Products of creativity include scientific theories, art, innovations, economic goods, institutions and biological adaptations. Usually, creativity is explained by two mechanisms: instructionism and selectionism (Cziko 1995). Instructionism is analogous to Lamarckism and represents the view that the environment (teacher, prices, trees, government) can impose adaptive (valuable) novelties directly on an entity (student, goods, giraffe's neck, society). According to selectionism (analogous to Darwinism), adaptive novelties arise through indirect mechanisms that generate independent variations representing possible adaptive novelties, and interaction with the environment chooses the most valuable variations.

Selectionism has been best studied in biological evolution. However, selectionist mechanisms underlie creativity in other domains as well, including antibody formation, learning, scientific development and entrepreneurship
(Cziko 1995, Metcalfe 1999, Ridley 2015). Studies have shown that instructionism is incompatible with the Second law of thermodynamics, perhaps the supreme law of nature (Elitzur 1994, Naess 2003). On the other hand, selectionism is both compatible and dependent on the Second law of thermodynamics (Eigen and Winkler 1993, Elitzur 1994). Therefore, it is highly likely that selectionist mechanisms underlie all creative processes (Chaitin 2012). It is only a historical coincidence that selectionism first was studied in biological evolution (Metcalfe 1999).

Selectionist mechanisms are based on three conditions. Firstly, there has to be variations. Secondly, environmental differences influence on both survival and copying of the variations. Thirdly, copies have to be similar (inheritance). It follows that if the error rate of copying exceeds the rate at which it is removed by selection, then creative evolution is impossible (Ridley 2000). Therefore, creativity is dependent on discrete units representing possible adaptive novelties (Deutsch 2011). Copying of analogous units is prone to excessive error rates of copying due to the Second law of thermodynamics.

Genes constitute the discrete units in biological evolution. In cultural evolution including science, art, knowledge and economic goods, selectionist mechanisms are based on possible adaptive (valuable) novelties represented by discrete units such as letters, numbers, words, bits or musical notation (Naess 2014).

Entrepreneurship depends on trial and error that requires voluntary interaction where entrepreneurs test new ideas 
(goods or services) on the market. There are many more ways to fail than to succeed. "In going beyond what is already known, one cannot but go blindly" (Campbell 1988). The price mechanisms represent the environment ensuring that the consumers' most urgent needs are satisfied (von Mises 1963). Entrepreneurs introduce blind variations and the price mechanisms is responsible for selective retention. Thus, economic growth is based on selectionist mechanisms.

By definition, the state's methods are ultimately built on coercion. The state's creative potential is therefore highly restricted. The state is unable to exploit the huge creative potential unleashed by independent, voluntary interaction utilizing literacy and money (profit and loss). Without private property it is impossible to make economic calculation and without economic calculation economic growth is highly restricted (von Mises 1963).

This also applies to laws, regulations and infrastructure. The state imposes top-down regulation employing instructionist mechanisms. Because of lack of both independent trial and error and an arena for independent selective retention, it is highly unlikely for the state to discover or create effective and valuable institutions and services. This implies that the state is implausible to be the cause of economic growth and human flourishing.

Unlike the state, civil society comprises independent actors, and an arena for selective retention. Both the state and civil society make use of written language. However, only civil society can use selectionist mechanisms rooted in discrete units (letters and words) represented by a historically increasingly effective written language techniques.

Of all the inventions, the written language is in a special position by providing the necessary scaffolding for discrete representations of knowledge including written descriptions of other inventions. This scaffolding enables selectionist processes in civil society and instructionist processes by government. However, only selectionist processes generate growth.

Studying history quantitatively can possibly shed further light on the significance of the state and written language for growth. Economic growth is based on investment, innovations and the testing of novel goods and services on the market. Thus, the rate of positive economic growth is a proxy variable for human creativity.

The aim of the present study was to investigate quantitatively the relation between economic growth, writing mechanisms and state organization. I hypothesized that the rate of positive economic growth in history correlates with evolution of better writing mechanisms including spreading of literacy, but not with state building whether despotic or non-despotic. The hypothesis was studied by using Ian Morris' calculation of energy capture as a proxy for economic growth and the sophistication of information technology including literacy rate as a proxy for the use of writing mechanisms through human history in the West (Morris 2013).

\section{Methods}

Table 1 shows the historical development of human beings divided in periods defined by the type of communication or organization of state/ society. It follows a timeline from Mesopotamia to ancient Greece, Roman Empire, and Western Europe until our time. Communication is divided into the following categories: oral, primitive written language, Greek and Latin alphabet, printing press, and digital revolution.

Organization of state/ society is divided into anarchy, a shackled or non-despotic state, and a despotic state as described by Acemoglu and Robinson. In a shackled state, power is shared between the elite and society (Acemoglu and Robinson 2019).

The Hunter gathering period represents the period from the first modern man 300,000 to 100,000 years ago until the first agricultural communities. Communication was oral. The period from 11,000 to 5,000 years ago is the time from the dawn of agriculture to the invention of primitive written language. The first cities arose with specialized artisans. Irrigation was invented. It is likely that the first written language was invented before the first state and probably used for trading, religion and registration of tribute (Scott 2017). The period of this primitive written language without state seems to have been short. The first states were based on grain production and written language (Scott 2017). The first hundreds of years after the advent of the state most people continued to live in stateless societies and traded with the states (Scott 2017). However, eventually the states became despotic and command economies were established (Scott 2017). About 3200 years ago, the Greek state collapsed for uncertain reasons (the Greek Dark Age). It was followed by anarchy and the written language disappeared (Acemoglu and Robinson 2019). The community most likely experienced stagnation. The Greek golden era followed shortly after the invention of the Greek alphabet (Ong 2001). This led to the formation of a democratic, shackled state in Athens. The Greeks experienced growth in economics, philosophy, art and science. The Roman Republic arose shortly afterwards. The Latin alphabet was constructed just in advance and the Republic represented a shackled state in which the power of the elite was held in check by civil society. The Roman Republic was characterized by growth (Carswell 2017). This growth stopped during the imperial era when the state became despotic (Morris 2013, Stark 2014). In the time after the fall of the empire, the Roman Empire was divided into several weak, non-despotic kingdoms dominated by Germanic tribes. It is possible that growth picked up somewhat when the exploitation by Rome ceased (Scott 2012, Scott 2017). Following the conquests of the Arabs, the Dark Middle Ages came into being where writing largely disappeared due to a lack of papyrus (Scott 
Table 1: Communication and organization of society state in different eras before present

\begin{tabular}{|c|c|c|}
\hline Era, years before present & Communication $^{1}$ & State $^{2}$ \\
\hline Hunting gathering, pre 11,000 & 0 & 0 \\
\hline Agriculture, $11,000-5000$ & 0 & 0 \\
\hline Advent of writing, ca. 5000 & 1 & 0 \\
\hline First states, 5000-3200 & 1 & 2 \\
\hline Greek dark era, 3200-2700 & 0 & 0 \\
\hline Greek golden era, $2700-2300$ & 2 & 1 \\
\hline Roman republic, $2500-2000$ & 2 & 1 \\
\hline Roman empire, 2000-1600 & 2 & 2 \\
\hline Roman collaps, 1600-1300 & 2 & 1 \\
\hline Dark middle age, $1300-1000$ & 1 & 0 \\
\hline Late middle age, $1000-570$ & 2 & 1 \\
\hline Printing press era, $570-200$ & 3 & 2 \\
\hline Industrial revolution, $200-20$ & 3 & 1 \\
\hline Digital era, 20-present & 4 & 1 \\
\hline
\end{tabular}

2012). For a period around the year 900, there were no states in Western Europe (Quigley 1966). From about the year 1000, states had re-established themselves and the written language was increasingly used. Introduction of paper in Europe in the 11th century probably contributed to this increase (Crespo and Vinas 1984). The states were small and some were republican as in Venice (Carswell 2017, Acemoglu and Robinson 2019). Europe experienced new economic growth and emerging empirical science saw the light of day (Stark 2014). In about 1450, Gutenberg invented the art of printing. This revolutionized communication between people in Western Europe. Science and art flourished. Economic growth increased, albeit to varying degrees. Absolute monarchy was established. From the year 1800, economic growth increased further and Western Europe led by England broke out of the Malthusian trap (Maddison 2004). Absolute monarchy ceased and states were chained by civil society gaining greater power over the elite. After the First and Second World Wars, states have again become stronger and increasingly regulated civil society. States are democratic, but with increasing despotic features. We are now in the era of the digital revolution.

Table 2 shows human history since the dawn of agriculture based on Ian Morris' calculation of energy capture by humans (both food, fuels and raw materials) and the sophistication of information technologies including growth of literacy in different historical periods in the West (Morris 2013).

The annual rate of growth of energy capture is calculated by dividing the change of energy capture in a period with the absolute energy capture at the end of the previous period divided by the number of years in the period.

The information technology variable is based on the calculation of literacy in each historical period multiplied by a multiplier representing speed and reach of information technololgy (Morris 2013). Morris used a constant multiplier for periods prior to $1800 \mathrm{CE}$. Thus, the information technology variable prior to $1800 \mathrm{CE}$ represents the rate of literacy in the population. In order to reflect the advent of the Greek alphabet and the printing press I made separate analyses multiplying the Morris' information technology variable by 2 from $600 \mathrm{BC}$ to $1500 \mathrm{CE}$ and by 3 from $1500 \mathrm{CE}$ to $1800 \mathrm{CE}$.

The organization of the society follows the tripartition of society into anarchy, shackled state and despotic state as described by Acemoglu and Robinson (Acemoglu and Robinson 2019). 
Table 2: Rate of growth of energy, information technology and state organization since the advent of agriculture

\begin{tabular}{|c|c|c|c|}
\hline Period & Growth of energy capture & Information technology & State \\
\hline $10,000 \mathrm{BC}$ & 0.000000 & 0.00 & 0 \\
\hline $9000 \mathrm{BC}$ & 0.000100 & 0.00 & 0 \\
\hline $8000 \mathrm{BC}$ & 0.000090 & 0.00 & 0 \\
\hline $7000 \mathrm{BC}$ & 0.000083 & 0.00 & 0 \\
\hline $6000 \mathrm{BC}$ & 0.000077 & 0.00 & 0 \\
\hline $5000 \mathrm{BC}$ & 0.000140 & 0.00 & 0 \\
\hline $4000 \mathrm{BC}$ & 0.000250 & 0.00 & 0 \\
\hline $3500 \mathrm{BC}$ & 0.000200 & 0.00 & 0 \\
\hline $3000 \mathrm{BC}$ & 0.000180 & 0.01 & 0 \\
\hline $2500 \mathrm{BC}$ & 0.000330 & 0.01 & 2 \\
\hline $2250 \mathrm{BC}$ & 0.000570 & 0.01 & 2 \\
\hline $2000 \mathrm{BC}$ & 0.000250 & 0.02 & 2 \\
\hline $1750 \mathrm{BC}$ & 0.000470 & 0.02 & 2 \\
\hline $1500 \mathrm{BC}$ & 0.000320 & 0.02 & 2 \\
\hline $1400 \mathrm{BC}$ & 0.000250 & 0.02 & 2 \\
\hline $1300 \mathrm{BC}$ & 0.000240 & 0.02 & 2 \\
\hline $1200 \mathrm{BC}$ & -0.000230 & 0.02 & 0 \\
\hline $1100 \mathrm{BC}$ & -0.000240 & 0.01 & 0 \\
\hline $1000 \mathrm{BC}$ & -0.000240 & 0.01 & 0 \\
\hline $900 \mathrm{BC}$ & 0.000250 & 0.02 & 0 \\
\hline $800 \mathrm{BC}$ & 0.000240 & 0.02 & 0 \\
\hline $700 \mathrm{BC}$ & 0.000240 & 0.02 & 0 \\
\hline $600 \mathrm{BC}$ & 0.000230 & 0.02 & 1 \\
\hline $500 \mathrm{BC}$ & 0.000450 & 0.03 & 1 \\
\hline $400 \mathrm{BC}$ & 0.000430 & 0.03 & 1 \\
\hline $300 \mathrm{BC}$ & 0.000830 & 0.03 & 1 \\
\hline $200 \mathrm{BC}$ & 0.000380 & 0.03 & 1 \\
\hline $100 \mathrm{BC}$ & 0.000740 & 0.04 & 1 \\
\hline 0 & 0.000690 & 0.04 & 1 \\
\hline $100 \mathrm{CE}$ & 0.000000 & 0.04 & 2 \\
\hline $200 \mathrm{CE}$ & -0.000300 & 0.04 & 2 \\
\hline $300 \mathrm{CE}$ & -0.000330 & 0.03 & 2 \\
\hline $400 \mathrm{CE}$ & -0.000170 & 0.03 & 2 \\
\hline $500 \mathrm{CE}$ & -0.000180 & 0.03 & 1 \\
\hline $600 \mathrm{CE}$ & -0.000700 & 0.02 & 1 \\
\hline $700 \mathrm{CE}$ & -0.000380 & 0.02 & 1 \\
\hline $800 \mathrm{CE}$ & 0.000000 & 0.02 & 0 \\
\hline $900 \mathrm{CE}$ & 0.000000 & 0.02 & 0 \\
\hline $1000 \mathrm{CE}$ & 0.000400 & 0.02 & 0 \\
\hline $1100 \mathrm{CE}$ & 0.000000 & 0.02 & 1 \\
\hline $1200 \mathrm{CE}$ & 0.000190 & 0.03 & 1 \\
\hline $1300 \mathrm{CE}$ & 0.000190 & 0.04 & 1 \\
\hline $1400 \mathrm{CE}$ & -0.000370 & 0.04 & 1 \\
\hline $1500 \mathrm{CE}$ & 0.000380 & 0.05 & 2 \\
\hline
\end{tabular}




\begin{tabular}{|l|c|c|c|}
$1600 \mathrm{CE}$ & 0.000740 & 0.07 & 2 \\
$1700 \mathrm{CE}$ & 0.001000 & 0.14 & 2 \\
$1800 \mathrm{CE}$ & 0.001900 & 0.29 & 2 \\
$1900 \mathrm{CE}$ & 0.014000 & 3.19 & 1 \\
$2000 \mathrm{CE}$ & 0.015000 & 250.00 & 1 \\
\hline
\end{tabular}

Adapted from Ian Morris (Morris 2013)

\section{Statistics}

The statistical analyses are based on the assumption that the rate of change of energy capture (Table 2) is a proxy variable for the rate of economic change. Furthermore, the information technology variable (Table 2) is assumed to reflect the sophistication of written language mechanisms.

In accordance with the hypothesis that the rate of positive economic growth in history correlates with evolution of better writing mechanisms and not with state building, analyses were limited to periods with positive rates of energy capture. Pearson's correlation test was used for univariate analyses.

Linear regression analyses were performed with the annual rate of change of energy capture as dependent variable and information technology and different state variables as independent variables. The State variable was defined as anarchy $=0$, shackled state $=1$ and despotic state $=2$. STATA 14.0 (Statacorp 4905 Lakeway Drive, College Station, Texas 77845 USA) was used for analyses.

\section{Results}

The correlation factor ( $r$ ) between information technology (IT) and the positive rate of growth of energy capture $(\mathrm{G})$ was $\mathrm{r}=.73, \mathrm{P}<.001$. Figure 1 shows a linear prediction model for the logarithm of positive $\mathrm{G}$ in relation to the logarithm of IT with $95 \%$ confidence intervals

Linear regression analyses using IT and different state variables as independent variables show that a positive rate of $\mathrm{G}$ was independently associated with IT and none of the state variables (Table 3 ).

Significant association between a positive rate of $\mathrm{G}$ and IT was found in linear regression analyses of all periods starting at 10,000 BC and ending between $300 \mathrm{BC}$ and $2000 \mathrm{CE}$ after adjusting for different state variables. In these regression analyses, no state variable was independently associated with a positive rate of $\mathrm{G}$.

Using the modified information technology variable did not change the above analyses.

Figure 2 shows the rate of economic growth, information technology and organization of society (anarchy, shackled state or despotic state) since the dawn of agriculture. It shows that improvement of information technology tends to be associated with a positive rate of energy capture. Parallel to this the development of a shackled state follows. Ultimately, the shackled state turns into a despotic state with a concomitant fall in the rate of energy capture (except after the invention of the printing press).

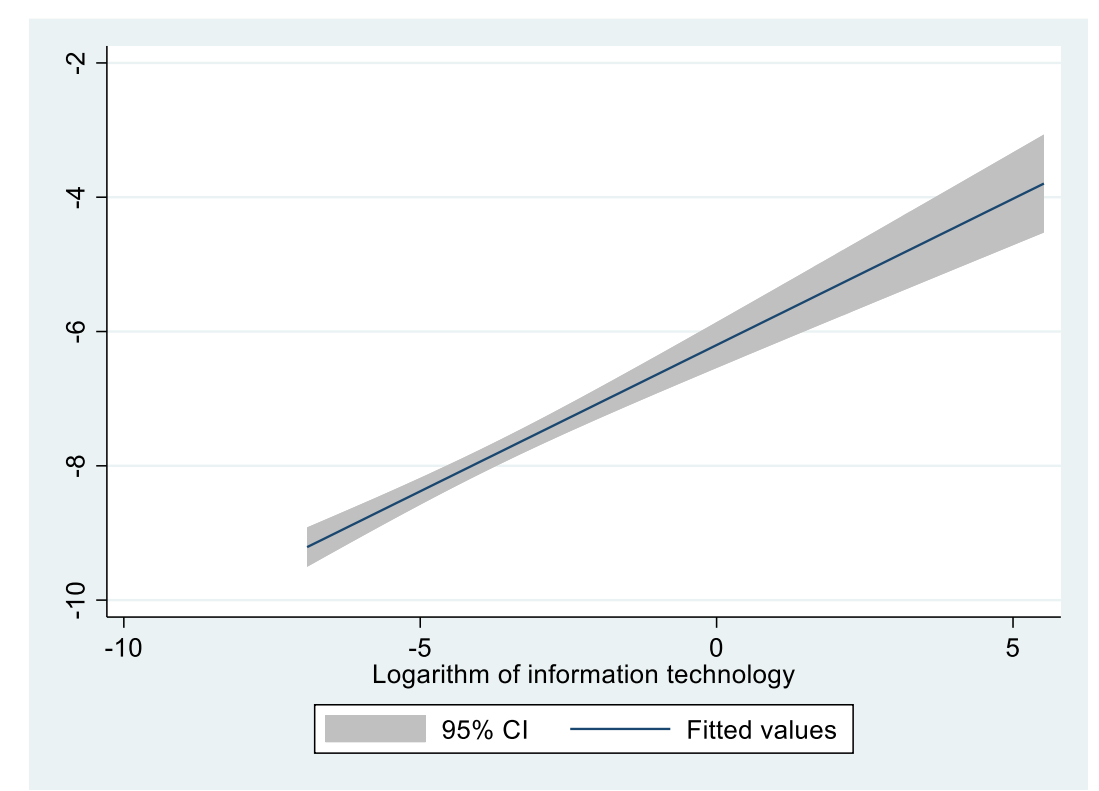

Figure 1: A linear prediction model for the logarithm of the rate of positive energy capture (Y-axis) in relation to the logarithm of information technology with 95\% confidence intervals 
Table 3: Regression analyses with the rate of positive growth of energy capture as dependent variable and different state variables

\begin{tabular}{|c|c|c|c|}
\hline & Partial r & $\mathrm{P}$ & R-squared \\
\hline \multirow[t]{2}{*}{ Information technology } & .72 & $<.001$ & \multirow{3}{*}{.55} \\
\hline & & & \\
\hline State $^{1}$ & .21 & .24 & \\
\hline \multirow[t]{2}{*}{ Information technology } & .71 & $<.001$ & \multirow{3}{*}{.54} \\
\hline & & & \\
\hline State (minus anarchy) & -.20 & .40 & \\
\hline \multirow[t]{2}{*}{ Information technology } & .71 & $<.001$ & \multirow{3}{*}{.56} \\
\hline & & & \\
\hline State (minus despotic state) & .28 & .19 & \\
\hline \multirow[t]{2}{*}{ Information technology } & .96 & $<.001$ & \multirow{3}{*}{.94} \\
\hline & & & \\
\hline State (minus shackled state) & .35 & .12 & \\
\hline \multirow[t]{2}{*}{ Information technology } & .72 & $<.001$ & \multirow{3}{*}{.55} \\
\hline & & & \\
\hline Anarchy versus any state ${ }^{2}$ & .21 & .24 & \\
\hline
\end{tabular}

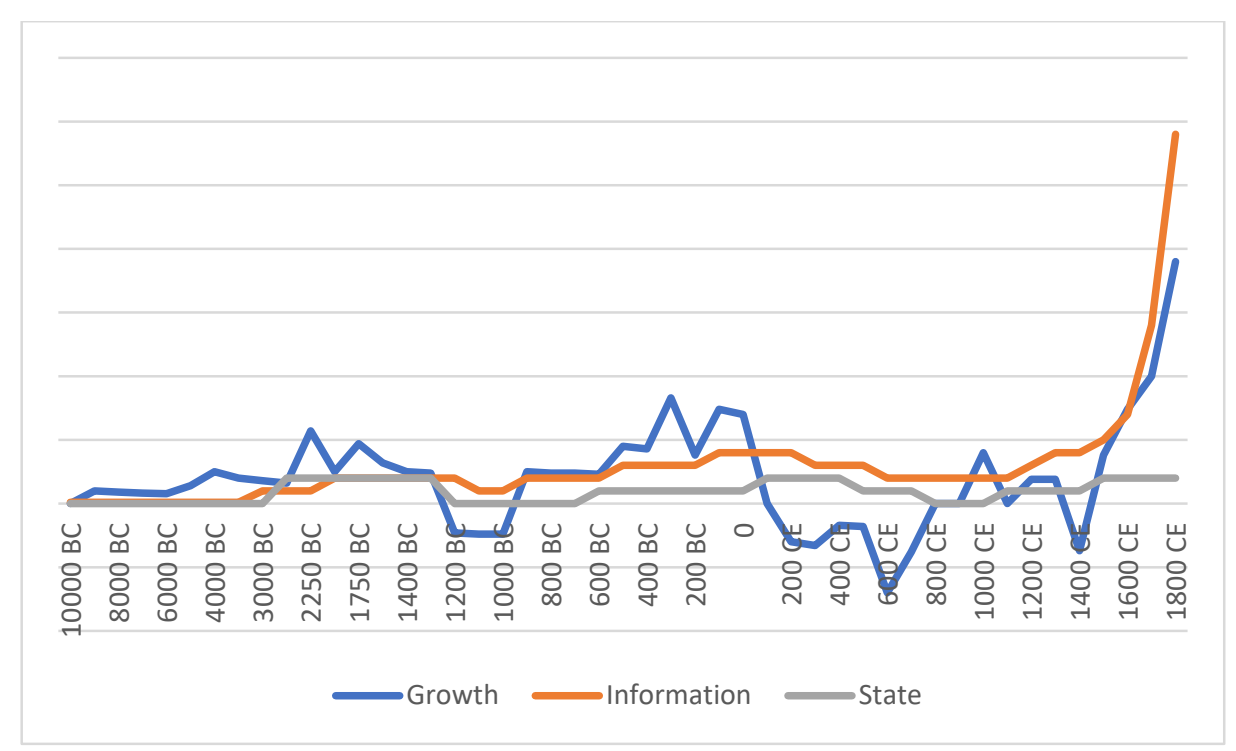

Figure 2: The rate of growth of energy capture, sophistication of information technology and organization of society since the dawn of agriculture

\section{Discussion}

Correlation is not the same as a causal relationship. However, if we assume that it is either development of information technology or degree of state dominance (shackled or despotic state) or both that explain the rate of positive economic growth, then the most reasonable interpretation of the above analyses is that the rate of positive economic growth is due to better information technology based on improving written language techniques and spreading of literacy. On the other hand, state organization whether shackled or despotic compared to anarchy does not seem to be independently associated with the rate of positive economic growth. This supports my hypothesis. Development of ever better written language technology and spreading of literacy is the cause for 
increasing rate of positive economic growth.

The statistical analyses are therefore consistent with the theoretical findings that creativity (visualized by rates of positive economic growth) is based on selectionist and not instructionist mechanisms (Naess 2003). Selectionist mechanisms build on independent trial and error of ideas tied to discrete units. The development of written language represents improvement in the use of knowledge stored by discrete units (letters and words) and this explains the rate of positive economic growth in periods with improving information technologies or spreading of literacy or both.

Most people believe that the state is necessary for growth and that anarchy leads to chaos (Acemoglu and Robinson 2019). This misunderstanding may come from the fact that the state is dependent on written language (Scott 2017). Our analyses strongly suggest that written language technology is necessary for growth. However, causal relationship between state and the positive rate of economic growth is spurious.

People living in oral societies are often bound by strong social norms that are incompatible with growth (Acemoglu and Robinson 2019). Many think that states helped people breaking out of this "cage of norms". However, it is more likely that written language caused the repeal of anti-creative norms. Thus, a critical tradition appeared in ancient Greece after the invention of the Greek alphabet. Also, the invention of the printing press unleashed an outburst of novel ideas resulting in the enlightenment, the scientific revolution and eventually the industrial revolution (Eisenstein 1983). This is consistent with the statistical analyses in this paper.

Figure 2 shows a repeating pattern through history. Positive economic growth follows large improvements in information technologies. Shortly thereafter, the formation of shackled or weak states appear and growth continues for some time, but eventually the states become despotic and growth declines. The despotic state disintegrates into anarchy. Eventually, improvement of information technology restarts positive economic growth in anarchic societies and the subsequent formation of new shackled states. This happened after the invention of writing in Mesopotamia, after the invention of the Greek alphabet in Greece and Latin alphabet in Rome, and after the reintroduction (or the increase) of writing around the year $1000 \mathrm{CE}$ in Western Europe possibly because of the introduction of paper. However, as despotic states were about to re-establish themselves, the printing press was invented in about $1450 \mathrm{CE}$. This led to a struggle between despotic states and the creative forces unleashed by the printing press ultimately causing the defeat of despotism and the rise of shackled nation states in the 19th century. Presently, we experience a struggle between creative forces set free by the digital revolution and the power of regulatory states with increasing despotic traits. Whether we will experience the victory of creativity as in the 19th century or the historically more frequent rise of despotism remains to be seen. Figure 2 shows that despotic states are associated with negative rates of energy capture. This is probably due to the introduction of command economies by despotic regimes (von Mises 1963).

Compatible with the present findings, a study of innovation rate per billion population, weighted for literacy showed spikes of innovation between $3000 \mathrm{BC}$ and $2000 \mathrm{BC}, 700$ $\mathrm{BC}$ and $100 \mathrm{CE}, 1200 \mathrm{CE}$ and $1400 \mathrm{CE}$, and $1500 \mathrm{CE}$ and present era (Gary 2014). Thus, there seems to be a correlation between spikes of innovation, growth of energy capture and improvement of information technology including literacy.

Of interest are reports on political fragmentation that show that cultural creativity is positively correlated with the number of independent states. Thus, political fragmentation characterized both Classical Greece and Renaissance Italy whereas empires tend to choke creativity (Simonton 2018).

Political fragmentation leads to competition and contributes to shackled states (Hoppe 1993).

Unlike China and the Ottoman Empire, competing states in Europe did not ban the printing press.

A strength of the present study is that the analyses are based on data compiled independently of the aim of the present study, and the data cover a period from the dawn of agriculture until the present time. It is likely that the rate of growth of energy capture is a proxy for the rate of economic growth. Thus, based on data compiled by Madison the correlation between the rate of energy capture and the rate of economic growth rate of GDP the last 2000 years is high (>.9) (Maddison 2007). The finding that a positive rate of energy capture is associated with information technology and not state variables is robust. This is because it holds for a multivariate analysis including the period from the dawn of agriculture until $300 \mathrm{BC}$, and for analyses of all successive periods beginning with the dawn of agriculture until the present time.

\section{Conclusion}

Both theoretical and historical analyses suggest that there is a causal relationship between the evolution of the written language technology and the rate of positive economic growth whereas there is no causal relationship between state building and the rate of positive economic growth.

\section{References}

1. Acemoglu, D. and J. A. Robinson (2019). The Narrow Corridor. New York, Penguin Press.

2. Campbell, D. T. (1988). Evolutionary epistemology. Evolutionary Epistemology, Rationality, and the Sociology of Knowledge. W. W. Bartley, III. Chicago, Open Court Publishing Company.

3. Carswell, D. (2017). Progress vs Parasites. London, An Apollo Book.

4. Chaitin, G. (2012). Proving Darwin. New York, Pantheon Books.

5. Crespo, C. and V. Vinas (1984). The Preservation and Restoration of Paper Records and Books. United Nations Educational, Scientific and Cultural Organization. 
6. Cziko, G. (1995). Without miracles. Cambridge, Massachusetts, The MIT Press.

7. Deutsch, D. (2011). The beginning of infinity. New York, Viking.

8. Eigen, M. and R. Winkler (1993). The Laws of the Game. Princeton, New Jersey, Princeton University Press.

9. Eisenstein, E. L. (1983). The Printing Revolution in Early Modern Europe. Cambridge, Cambridge University Press.

10. Elitzur, A. C. (1994). "Let there be life." Journal of Theoretical Biology 168: 429-459.

11. Gary, B. L. (2014). Genetic Enslavement: A Call to Arms for Individual Liberation. Hereford, AZ, Reductionist Publications.

12. Hoppe, H. H. (1993). "Nationalism and Secession." Chronicles(November): 23-25.

13. Maddison, A. (2004). Growth and Interaction in the World Economy. Washington, D.C., The AEI Press.

14. Maddison, A. (2007). Contours of the World Economy, 1 - 2030 AD. Oxford, Oxford University Press.

15. Metcalfe, J. S. (1999). Darwinian Dynamics: Economics and Creative Destruction. London, Routledge.

16. Morris, I. (2013). The Measure of Civilization. Princeton, Princeton University Press.
17. Naess, H. (2003). "Instructionism is impossible due to the second law of thermodynamics." Journal of Mind and Behavior 24: 57-66.

18. Naess, H. (2014). "The Mechanisms of Cumulative Social Evolution." Paripex 3(5): 57-61.

19. Ong, W. J. (2001). Orality and Literacy. London, Routledge.

20. Quigley, C. (1966). Tragdey \& Hope. New York, The Macmillan Company.

21. Ridley, M. (2000). Mendel's demon. London, Weidenfeld \& Nicolson.

22. Ridley, M. (2015). The Evolution of Everything. London, Fourth Estate.

23. Scott, E. (2012). Mohammed \& Charlemagne Revisited. Nashville, New English Review Press.

24. Scott, J. C. (2017). Against the Grain, Yale University Press.

25. Simonton, D. K. (2018). Creativity in Sociocultural Systems: Cultures, Nations, and Civilizations. The Oxford Handbook of Group Creativity and Innovation. P. B. Paulus and B. A. Nijstad. Oxford, Oxford University Press.

26. Stark, R. (2014). How the West Won. Wilmington, Delaware, ISI Books.

27. von Mises, L. (1963). Human Action. Chicago, Contemporary Books, Inc.

Citation: Naess, Halvor MD, PhD "Evolution of written language technology and not state building causes positive economic growth". American Research Journal of History and Culture, vol 6, no. 1, 2020, pp. 1-8.

Copyright (c) 2020 Naess, Halvor. This is an open access article distributed under the Creative Commons Attribution License, which permits unrestricted use, distribution, and reproduction in any medium, provided the original work is properly cited. 